\title{
Persistent knee pain after uncomplicated total knee arthroplasty secondary to undiagnosed spondylotic myelopathy: a case report
}

\author{
Ziva Petrin $\left.{ }^{1}\right)^{1}$ Mitchell Freedman ${ }^{2}$
}

Received: 6 June 2019 / Accepted: 28 June 2019

(c) International Spinal Cord Society 2019

\begin{abstract}
Introduction Knee osteoarthritis and cervical spondylotic myelopathy are both frequent disorders in the aging patient. Total knee arthroplasty is an increasingly common surgical procedure, with approximately $20 \%$ of patients describing persistent knee pain after the procedure, for which it is often difficult to find a cause. We review known reasons for pain after total knee arthroplasty and present a new clinically challenging case of persistent knee pain due to previously undiagnosed cervical spondylotic myelopathy.

Case presentation Our patient presented with painful knee spasms after an uncomplicated total knee arthroplasty. Her workup revealed cervical spondylotic myelopathy with isolated changes in tone in the affected extremity as well as weakness and atrophy in non-painful limbs. Her clinical status improved after cervical decompression and fusion. We perform a literature review for prior reports of isolated knee pain due to cervical spondylotic myelopathy and find no previous reported association with total knee arthroplasty.

Discussion Cervical spondylotic myelopathy is the most common spinal cord disorder in older adults. Incidence increases with age and the clinical manifestations may present with a variety of neurological findings. Careful musculoskeletal and neurologic examination is critical to an accurate and timely diagnosis.
\end{abstract}

\section{Introduction}

An estimated 4.7 million patients were living with total knee arthroplasty (TKA) in 2010 [1, 2], with annual replacement rates of approximately 700,000, with projections to increase to 3.48 million annual procedures by the year 2030 [3]. Although total knee replacement is effective in improving outcomes in most patients, studies have found that up to $20 \%$ of patients are dissatisfied with the results of their TKA $[4,5]$. In a study of younger patients who underwent a surgically successful TKA (age range 19-60 years, mean age 54 years), only $66 \%$ of patients felt that their knee felt normal, with $34 \%$ experiencing residual symptoms following TKA, including persistent pain, stiffness, swelling, or functional limitations, and with $10 \%$ of

Ziva Petrin

ziva.petrin.work@gmail.com

1 Division of Physical Medicine and Rehabilitation, University of Utah, Salt Lake City, UT, USA

2 Rothman Institute, Philadelphia, PA, USA patients expressing dissatisfaction with the overall function of their knee after the procedure [6].

There are numerous causes of persistent pain after joint replacement and multiple authors have outlined diagnostic approaches to investigate pain after TKA [7-10]. In 2014, Vince [11] described nine modes of failure of the total replacement knee. The first eight modes delineate surgical or local complications, with the ninth mode categorized as "no diagnosis" or unexplained pain. The patient with unrelieved pain or new pain after joint replacement must first be evaluated for the first eight modes, including infection, tendon rupture, contracture, tibial-femoral instability, patellar tracking abnormality, osteolysis or fracture, and hardware failure. With newer surgical techniques and materials, infection has become the most common reason for failure after TKA [8].

After mechanical, infectious, and vascular etiologies have been ruled out, neuropathic pain should be considered in the differential [12]. This is especially indicated in the presence of clinical findings associated with neurological involvement. Neurologic differential diagnosis includes radiculopathy and peripheral nerve lesions, including lumbar, lumbosacral, sciatic, and femoral nerve lesions. 
Complex regional pain syndrome must be a consideration as well [12]. Spinal cord pathology and focal or global central nervous system lesions are less likely to contribute to focal knee area pain but have been reported [13-17].

We present a clinically challenging case of post-TKA persistent pain with associated abnormal neurological findings. A diagnosis of cervical spondylotic myelopathy was ultimately found to be the cause of the localized knee pain secondary to spasticity causing recurrent knee flexion. We perform a literature review of similar cases and briefly review the diagnosis and treatment of cervical spondylotic myelopathy.

\section{Case presentation}

A 65-year-old female initially presented to an outpatient orthopedic clinic with a complaint of severe right knee pain intractable to medication and conservative management. Her past medical history included hypertension. Clinical evaluation was consistent with knee osteoarthritis, and anteroposterior, lateral, and patellar views of the right knee confirmed advanced degenerative arthritis. She underwent an uncomplicated TKA using a medial parapatellar approach with a computer-assisted instrumentation system.

Post-operatively, she complained of severe posterior knee pain and spasm in the area of the knee. There were no associated paresthesia, systemic symptoms, skin sudomotor, or vascular changes. Radiographs of the knee revealed satisfactory position and alignment of the mechanical components with no signs of loosening of hardware or infection. She was seen multiple times in the orthopedic office over the next month due to persistent muscle spasm with involuntary flexion and extension of her knee with associated posterior knee pain. Diazepam and cyclobenzaprine offered no relief.

She was referred for physiatric evaluation for persistent spasm and 10/10 pain with knee extension. At that time, she had no pain at rest but complained of cyclical and persistent $10 / 10$ painful spasms that would wake her up at night. She denied sensation changes or paresthesia. Physical examination revealed no color or temperature changes of the knee. Deep tendon reflexes were found to be brisk in the bilateral triceps and wrist extensors, as well as in the left quadriceps. The Babinski reflex was downgoing. There was a positive Hoffmann sign on the right with decreased strength of $4 / 5$ in the entire right arm with mild wasting of intrinsics but otherwise preserved muscular strength of the extremities.

Magnetic resonance imaging (MRI) of the cervical spine revealed multilevel spondylosis worst at $\mathrm{C} 4-\mathrm{C} 5$, with grade I degenerative retrolisthesis with disk herniation causing marked degree central spinal canal stenosis at C4-C5 and
C5-C6, with myelomalacia and cord edema. MRI of the brain revealed a small focal fusiform aneurismal dilatation, $3 \mathrm{~mm}$ in diameter and $7 \mathrm{~mm}$ in length of the left middle cerebral artery branch distal to the M1 segment. This incidental finding was thought unlikely to be contributory to the patient's complaints. These findings suggested the cervical spondylotic myelopathy as the most likely cause of painful spasms in the knee area.

She had minimal interim improvements in pain and stiffness with baclofen and physical therapy. Surgical cervical spine decompression was recommended to relieve cord compression. Surgery was refused for approximately 4 months, during which time her functional status significantly declined. She required a walker due to her spastic gait. She additionally developed shoulder pain. Five months after her initial knee replacement surgery, she agreed to undergo a posterior cervical decompression at $\mathrm{C} 3-\mathrm{C} 7$ with bilateral lateral foraminectomy and fusion from $\mathrm{C} 3$ to $\mathrm{T} 1$ with pedicular fixation, lateral mass instrumentation, and local bone graft.

She had a satisfactory outcome following the cervical decompression, with post-operative improvement in her leg tone and leg pain but with persistent mild neuropathic pain in the arms. She was able to return to work 10 months after her initial knee replacement surgery.

\section{Discussion}

Isolated knee area pain thought to be due to cervical pathology has been reported [13, 14, 16, 17]. Pain in the lower extremities may be secondary to spinal cord compression or myelopathy [18]. Cervical spondylotic myelopathy is a condition in which narrowing of the spinal canal and compression of the spinal cord occur due to degenerative changes, such as facet hypertrophy, disk herniation, hypertrophy or ossification of the longitudinal ligaments, and other degenerative changes [19].

The incidence of cervical spondylotic myelopathy is estimated at 1.6/100,000 population [20] and contributes to approximately $23.6 \%$ of cases of non-traumatic spinal cord injury (SCI) [21]. The incidence of radiologic findings of spinal cord impingement in asymptomatic individuals increases with age and has been described as occurring in $16 \%$ of patients aged $<64$ years and in $26 \%$ in those aged $>64$ years [22]. Spinal cord compression with findings of hyperintense T2 intraparenchymal cord signal on MRI is found in nearly all patients with clinical myelopathy [23]. However, not all patients with radiological findings of spinal cord compression have clinical signs of myelopathy, and this is attributed to the influence of the length of time of compression, with increasing duration of compression being associated with development of clinical symptoms [23]. 
Other studies have noted that approximately $5-8 \%[24,25]$ of patients with known radiographic cervical stenosis will progress annually from neurologically normal to clinically myelopathic. Patients with cervical spondylotic myelopathy have been noted to develop symptomatic SCI at a rate of approximately $0.2 \%$ per year [26], while other studies have shown variable natural progression of the condition $[19,27]$.

Treatment for spondylotic myelopathy is surgical decompression and fusion followed by rehabilitation. Dependent on length and severity of cord damage, surgical decompression may fully relieve symptoms. In more long-standing cases, the clinical cord damage may be irreversible, and the patient may have persistent SCI symptoms such as weakness, myelopathic gait, neurogenic bowel and bladder, or isolated long tract findings, such as persistent hyperreflexia and spasticity on clinical exam $[19,28]$.

Although cervical stenosis in the setting of degenerative changes can be theoretically worsened with dynamic neck movements required for intubation or static positions during surgery, there is minimal literature suggesting an association or correlation with onset of symptomatic myelopathy after surgical procedures. There are very limited case reports of acute post-surgical myelopathy [29, 30]. It is most likely that the patient had subclinical myelopathy prior to the knee replacement, and the post-operative knee pain acted as a nociceptor, which exacerbated spasticity and extensor tone, which in turn resulted in a vicious cycle of pain and spasm.

To our knowledge, this is the first reported case of postTKA knee pain and spasm due to cervical spondylotic myelopathy. Both cervical spondylosis and osteoarthritis of the knee are common in the general population. There is no current literature to suggest that surgical procedures acutely worsen the cervical stenosis and lead to symptomatic myelopathy. Cervical myelopathy with minimal symptomatology can be exacerbated with a nociceptive stimulus such as a surgical procedure. Worsened spasticity can then contribute to a reverberating cycle of pain and spasm.

Evaluation of extremity pain in patients before and after joint replacement should include neurological causes of pain in the differential diagnosis. A thorough history and physical must be performed including both a musculoskeletal and neurologic examination. Upper motor neuron or lower motor neuron findings should be evaluated and placed into clinical context.

\section{Compliance with ethical standards}

Conflict of interest The authors declare that they have no conflict of interest.
Publisher's note: Springer Nature remains neutral with regard to jurisdictional claims in published maps and institutional affiliations.

\section{References}

1. Weinstein AM, Rome BN, Reichmann WM, Collins JE, Burbine SA, Thornhill TS, et al. Estimating the burden of total knee replacement in the United States. J Bone Jt Surg Am. 2013;95:385-92. https://doi.org/10.2106/JBJS.L.00206.

2. Kremers HM, Larson DR, Crowson CS, Kremers WK, Washington RE, Steiner CA, et al. Prevalence of total hip and knee replacement in the United States. J Bone Jt Surg Am. 2014;97:1386-97. https://doi.org/10.2106/JBJS.N.01141.

3. Kurtz S. Projections of primary and revision hip and knee arthroplasty in the United States from 2005 to 2030. J Bone Jt Surg 2007;89:780. https://doi.org/10.2106/JBJS.F.00222.

4. Scott CEH, Howie CR, MacDonald D, Biant LC. Predicting dissatisfaction following total knee replacement: a prospective study of 1217 patients. J Bone Jt Surg Br 2010;92:1253-8. https:// doi.org/10.1302/0301-620X.92B9.24394.

5. Bourne RB, Chesworth BM, Davis AM, Mahomed NN, Charron KDJ. Patient satisfaction after total knee arthroplasty: who is satisfied and who is not? Clin Orthop Relat Res 2010;468:57-63. https://doi.org/10.1007/s11999-009-1119-9.

6. Parvizi J, Nunley RM, Berend KR, Lombardi AV, Jr, Ruh EL, Clohisy JC, et al. High level of residual symptoms in young patients after total knee arthroplasty knee. Clin Orthop Relat Res. 2014;472:133-7. https://doi.org/10.1007/s11999-013-3229-7.

7. Momoli A, Giarretta S, Modena M, Micheloni GM. The painful knee after total knee arthroplasty: evaluation and management. Acta Biomed 2017;88:60-67. https://doi.org/10.23750/abm. v88i2-S.6515.

8. Lum ZC, Shieh AK, Dorr LD. Why total knees fail-a modern perspective review. World J Orthop. 2018;9:60-4. https://doi.org/ 10.5312/wjo.v9.i4.60.

9. Bonnin MP, Basiglini L, Archbold HAP. What are the factors of residual pain after uncomplicated TKA? Knee Surg Sports Trauma Arthrosc 2011;19:1411-7. https://doi.org/10.1007/ s00167-011-1549-2.

10. Hofmann S, Seitlinger G, Djahani O, Pietsch M. The painful knee after TKA: a diagnostic algorithm for failure analysis. Knee Surg Sports Trauma Arthrosc 2011;19:1442-52. https://doi.org/10. 1007/s00167-011-1634-6.

11. Vince KG. The problem total knee replacement: systematic, comprehensive and efficient evaluation. Bone Jt J 2014;96B:105-11. https://doi.org/10.1302/0301-620X.96B11.34531.

12. Kosy JD, Middleton SWF, Bradley BM, Stroud RM, Phillips JRA, Toms AD. Complex regional pain syndrome after total knee arthroplasty is rare and misdiagnosis potentially hazardousprospective study of the new diagnostic criteria in 100 patients with no cases identified. J Knee Surg 2018;31:797-803. https:// doi.org/10.1055/s-0037-1615746.

13. Ross MD, Elliott R. Cervical cord compressive myelopathy in a man with a primary complaint of knee pain. J Spinal Cord Med 2010;33:431-4. https://doi.org/10.1080/10790268.2010. 11689724.

14. Neo M, Ido K, Sakamoto T, Matsushita M, Nakamura T. Cervical disc herniation causing localized ipsilateral popliteal pain. J Orthop Sci 2002;7:147-50. https://doi.org/10.1007/s776-002$8437-2$.

15. Ito T, Homma T, Uchiyama S. Sciatica caused by cervical and thoracic spinal cord compression. Spine (Philos $\mathrm{Pa}$ 1976) 1999;24:1265-7. 
16. Chan CK, Lee H-Y, Choi W-C, Cho JY, Lee S-H. Cervical cord compression presenting with sciatica-like leg pain. Eur Spine J 2011;20(S2):217-21. https://doi.org/10.1007/s00586-010-1585-5.

17. Akhavan-Sigari R, Rohde V, Alaid A. Cervical spinal canal stenosis and central disc herniation $\mathrm{c} 3 / 4$ in a man with primary complaint of thigh. Pain J Neurol Surg Rep 2013;74:101-4. https://doi.org/10.1055/s-0033-1349202.

18. Langfitt TW, Elliott FA. Pain in the back and legs caused by cervical spinal cord compression. JAMA 1967;200:382. https:// doi.org/10.1001/jama.1967.03120180070010.

19. Kalsi-Ryan S, Karadimas SK, Fehlings MG. Cervical spondylotic myelopathy: the clinical phenomenon and the current pathobiology of an increasingly prevalent and devastating disorder. Neuroscientist 2013;19:409-21. https://doi.org/10.1177/1073858412467377.

20. Boogaarts HD, Bartels RH. Prevalence of cervical spondylotic myelopathy. Eur Spine J. 2015;24:139-41. https://doi.org/10. 1007/s00586-013-2781-x.

21. Moore AP, Blumhardt LD. A prospective survey of the causes of non-traumatic spastic paraparesis and tetraparesis in 585 patients. Spinal Cord 1997;35:361-7.

22. Teresi LM, Lufkin RB, Reicher MA, Moffit BJ, Vinuela FV, Wilson GM, et al. Asymptomatic degenerative disk disease and spondylosis of the cervical spine: MR imaging. Radiology. 1987;164:83-88. https://doi.org/10.1148/radiology.164.1.3588931.

23. Harrop JS, Naroji S, Maltenfort M, Anderson DG, Albert T, Ratliff JK, et al. Cervical myelopathy: a clinical and radiographic evaluation and correlation to cervical spondylotic myelopathy. Spine (Philos Pa 1976). 2010;35:620-4. https://doi.org/10.1097/ BRS.0b013e3181b723af.

24. Wilson JR, Barry S, Fischer DJ, Skelly AC, Arnold PM, Riew KD, et al. Frequency, timing, and predictors of neurological dysfunction in the nonmyelopathic patient with cervical spinal cord compression, canal stenosis, and/or ossification of the posterior longitudinal ligament. Spine (Philos Pa 1976). 2013;38(22 Suppl 1):S37-54. https:// doi.org/10.1097/BRS.0b013e3182a7f2e7.

25. Bednarik J, Kadanka Z, Dusek L, Kerkovsky M, Vohanka S, Novotny $\mathrm{O}$, et al. Presymptomatic spondylotic cervical myelopathy: an updated predictive model. Eur Spine J. 2008;17:421-31. https://doi.org/10.1007/s00586-008-0585-1.

26. Chen LF, Tu TH, Chen YC, Wu JC, Chang PY, Liu L, et al. Risk of spinal cord injury in patients with cervical spondylotic myelopathy and ossification of posterior longitudinal ligament: a national cohort study. Neurosurg Focus. 2016;40:E4. https://doi. org/10.3171/2016.3.FOCUS1663.

27. Sheikh Taha AM, Shue J, Lebl D, Girardi F. Considerations for prophylactic surgery in asymptomatic severe cervical stenosis: review article. HSS J. 2015;11:31-5. https://doi.org/10.1007/ s11420-014-9426-4.

28. Tetreault LA, Kopjar B, Vaccaro A, Yoon ST, Arnold PM, Massicotte EM, et al. A clinical prediction model to determine outcomes in patients with cervical spondylotic myelopathy undergoing surgical treatment: data from the prospective, multicenter AOSpine North America study. J Bone Jt Surg Am. 2013;95:1659-66. https://doi.org/10.2106/JBJS.L.01323.

29. Xiong W, Li F, Guan H. Tetraplegia after thyroidectomy in a patient with cervical spondylosis: a case report and literature review. Medicine (Baltimore) 2015;94:1-5. https://doi.org/10. 1097/MD.0000000000000524.

30. Kudo T, Sato Y, Kowatari K, Nitobe T, Hirota K. Postoperative transient tetraplegia in two patients caused by cervical spondylotic myelopathy. Anaesthesia 2011;66:213-6. https://doi.org/10.1111/ j.1365-2044.2010.06562.x. 